\title{
Can we learn anything from China about Education in Mathematics?
}

Jenny Field

Department of Primary Education, University of Greenwich

We cannot deny that some areas of South East Asia do better than the UK in international mathematics tests. Tests, including TIMSS (Trends in International Mathematics and Science Study) and PISA (Programme for International Student Assessment) demonstrate that Shanghai and Singapore continue to hold top ranking positions, while children in England appear to be falling behind. The financial costs to society of an innumerate population are considerable, 'with one quarter of national GDP resulting from the mathematics-based financial services sector' (Williams, 2008). Indeed, those of us teaching in Higher and Further Education settings may also be aware of a decline in our students' mathematical abilities, with evidence to suggest that some universities are both 'marginalising the mathematical content' on degree courses, owing to students' lack of basic mathematics, and understating the level of mathematics needed to study a particular subject through fear of decreasing the number of applications (Norris, 2012). The knock-on effect of this could be to make our graduates less employable and our nation less able to keep pace and compete globally. The Confederation of British Industry reports that only $30 \%$ of employers are very satisfied with numeracy skills (CBI, 2009). So, with such high stakes, it is important to examine what areas of South East Asia are doing to reap such outstanding results. What could we learn? And what part does culture play in influencing success?

Our Government is presently keen to explore practices in Shanghai which could raise standards in the UK. In 2013, The Department for Education, co-ordinated by the National Centre for Excellence in the Teaching of Mathematics (NCETM), funded the creation of thirty-four National Maths Hubs charged with leading improvement in their local schools. These hubs bring together professionals in collaborative national networks, locally led by an outstanding school or college. In 2014/15, a key focus has been on a 'National Shanghai Exchange Programme', with representatives from each hub visiting Shanghai and Shanghai teachers subsequently coming to teach in the UK.

In spring 2015, I observed two such teachers from Shanghai and did note that their practice differed in some ways from that to be found here. Indeed, my observations dispelled many of my own pre-conceived ideas. I witnessed an approach unlike our often-used pedagogical structure of 'first the teacher will explain and then the children will do'. Instead, what came to mind was the Chuckle Brothers' phrase 'to me to you': the teacher did not let go of the children for longer than ten minutes and the learning went back and forth, with regular interactive assessment of what had been learned before progressing forward again.

This led me to reflect that, when our children are left to work independently for forty minutes or more during a lesson, whole-class assessment of learning is more likely to be summative than formative, whereas the Shanghai approach was a continuous focus on engaging children in high-quality explanatory and exploratory talk; a common phrase used by these teachers is 'the answer is only the beginning' (Schleppenbach et al, 2007). 
A key aspect of their pedagogical approach, which will be controversial in the UK, is the lack of differentiation. Their pedagogical practice focuses on keeping the class together through a 'Mastery Curriculum' where depth of understanding replaces accelerated learning. The phrase 'mastery learning' was coined by Benjamin Bloom in the 1970s to describe the mastering of a concept before moving on; this involves deeper understanding, flexibility, application and synthesis and aims to reduce the achievement gaps often seen between students (Stevenson et al, 1992). Progressive examples are carefully chosen by mathematics experts at a national level, to enable students to reason and generalise. Professor David Reynolds (2014) suggests that in the UK our more random approach to examples, particularly in text books, often demonstrates just one way of thinking, with numerous examples that lack progression, reasoning and conceptual understanding. In Shanghai, there is consistent focus on conceptual understanding, with clear models and images. An example of this is their approach to equality signs... not a 'hungry crocodile' to be seen!

\section{Shanghai Approach}

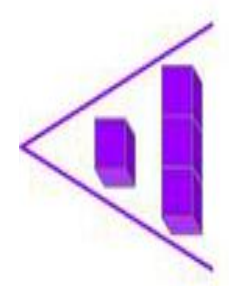

Approach often used in England

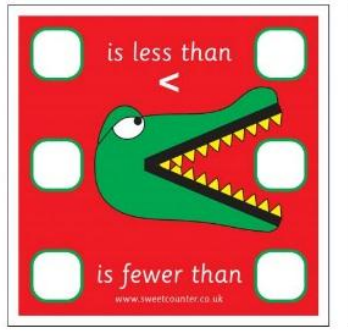

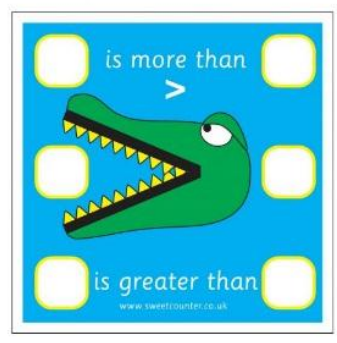

Figure 1: Equality signs

Other Chinese representations include 'the bar model' (Hoven et al, 2007). Children become familiar with nationally-consistent representation, on which the concepts themselves get progressively more difficult each year. Approaches to modelling in the UK tend to be more ad hoc and less progressive and cohesive across the whole school.

\section{Ratio using the Bar Model}

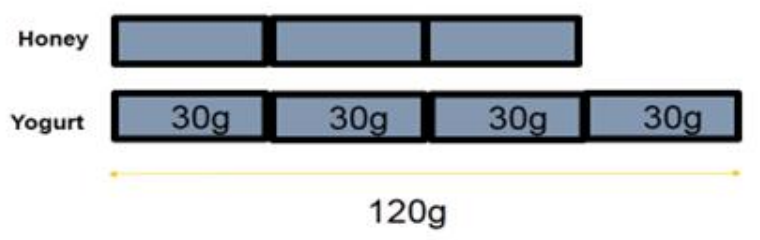

A herbal skin remedy uses honey and yoghurt in the ratio $3: 4$

How much honey is needed to mix with $120 \mathrm{~g}$ of yoghurt?

Figure 2: Ratio using the bar model 
Perhaps at this point we should consider that, in the 1960s, China was not doing at all well in the teaching of mathematics. There followed a national comprehensive review of the curriculum, focusing on the work of educational theorists including Bruner, Skemp, Vygotski and Dienes. So it appears that much of the knowledge that we ourselves value in education is actually integrated within their curriculum - we by contrast have had a more random approach to embedding this theory into our own practice.

So, should we just import their practices wholesale? Before we consider this, we need to reflect on some key differences between teacher training in the UK and that in China and between each country's expectations and organisation of the teaching of mathematics.

Chinese teacher training is completely government-controlled and children are taught by maths specialists in primary schools, a huge contrast to general UK policy. Crucially, this allows teachers to develop their subject knowledge beyond that of generalist primary teachers in the UK, giving all children a consistently strong early start (Merttens, 2015). Their teacher training takes up to five years, whilst we appear to be moving towards an era of devaluing the profession, with the introduction of more unqualified teachers - the NUT reports that, in 2013, 13\% of teachers in Free Schools were unqualified.

Teachers in China are also required to undertake regular high-quality CPD, including sabbaticals. They generally teach only two or three lessons each day - crucially allowing them to mark children's work quickly and, in the same afternoon, pick up on those children who have not fully understood before moving on the next day; differentiation is therefore not such an issue.

There has also been curriculum stability in China over many decades - content is honed at a national level by mathematics specialists, with an eye to perfecting what exists rather than making wholesale change - an approach much longed for by the teaching profession in England.

The Chinese school day is much longer and is regularly followed by home tutoring. Many children have tuition before they begin formal school at 7 and so the wide gap we experience in Foundation Stage is not present.

In terms of student well-being, there is evidence that educational pressures could be part of the reason for high suicide rates among the young in China (Chelala 2014; The Guardian, 2015). The two countries also have different attitudes to the philosophy behind the teaching of mathematics: China favours uniformity, whilst the UK prefers to develop individuality and creativity.

It is clearly important that our government does not select just those parts of Shanghai practice that will bring excessive pressure on our teachers and children, or those that merely seem to involve less expenditure, but, instead, that it makes real investment in changes that will apply relevant and beneficial aspects of the Chinese approach; with intelligent interpretation and application at a national level, we could be at the cusp of a very significant improvement to UK mathematics pedagogy. With the government's financial support, more stability, a national programme of continuing CPD and some reductions in content in our National Curriculum to allow for deeper learning, we could adapt the best of Chinese practices and combine them with the best of ours to create a more effective and dynamic curriculum. Over time, we might then also see an improvement in the mathematical ability of 
our young adults entering higher and further education, with increased opportunities for success in a $21^{\text {st }}$ century global economy.

\section{Reference list}

Bloom, B. S. (1971) 'Mastery learning.' In: J. H. Block (Ed.), Mastery learning: Theory and practice. New York: Holt, Rinehart \& Winston, 47-63.

CBI Confederation of British Industry (2009) 'Future Fit: Preparing Graduates for the world of work.' Available at: http://www.cbi.org.uk/media/1121435/cbi uuk future fit.pdf (Accessed: 13 July 2015).

Chelala, C. (2014) 'Will China be able to curb adolescent suicide?' The Globalist, 20 July 2014. Available at: http://www.theglobalist.com/will-china-be-able-to-curb-adolescentsuicide/ (Accessed: 09 May 2015).

Hoven, J. and Garelick, B. (2007) 'Singapore Math: Simple or Complex? Using the Bar Model Approach.' Educational Leadership 65, 3 (November 2007).

Merttens, R. (2015) 'Why are we blindly following the Chinese approach to teaching maths?' Guardian, 10 February 2015. Available at: http://www.theguardian.com/teachernetwork/2015/feb/10/chinese-teaching-primary-maths (Accessed: 10 May 2015).

Norris, E. (2012) Solving the maths problem: international perspectives on mathematics education. RSA The Royal Society for Encouragement of Arts, Manufactures and Commerce, 11. Available at:

https://www.thersa.org/globalassets/pdfs/reports/rsa maths report 102 12.pdf (Accessed: 13 July 2015).

National Centre for Excellence in the Teaching of Mathematics (NCETM). Available at: https://www.ncetm.org.uk/ (Accessed: 01 May 2015).

National Union of Teachers (NUT). Available at: https://www.teachers.org.uk/edufacts/freeschools (Accessed: 13 July 2015).

Reynolds, D. (2014) 'What's the evidence on Shanghai maths, expert reaction...' Education Media Centre. Available at: http://educationmediacentre.org/newsreactions/whats-theevidence-on-shanghai-maths-expert-reaction/ (Accessed: 01 May 2015).

Schleppenbach, M. and Perry, M. (2007) 'The Answer Is Only the Beginning: Extended Discourse in Chinese and U.S. Mathematics Classrooms.' Journal of Educational Psychology: American Psychological Association 99, 2, 380-396.

Stevenson, H. W., and Stigler, J. W. (1992) The learning gap. New York: Summit.

Williams, P. (2008) Independent Review of Mathematics Teaching in Early Years Settings and Primary Schools London: DCSF Publications. 